\title{
O ESTUDO DA CULTURA PELA ANÁLISE DO COMPORTAMENTO E A OBRA DE SIGRID GLENN
}

\author{
THE STUDY OF CULTURE IN BEHAVIOR ANALYSIS AND THE WORK OF SIGRID GLENN
}

\author{
ANGELO A. S. SAMPAIO* \\ Universidade Federal do Vale do São Francisco e Universidade de São PaUlo, Brasil
}

\author{
FELIPE L. LEITE \\ UNIVERSIDADE FEDERAL DO PARÁ, BRASIL
}

\section{RESUMO}

Apesar de seu foco no estudo do comportamento de organismos individuais, a Análise do Comportamento tem tratado há décadas de fenômenos sociais e culturais. Apenas na década de 1980, porém, começou-se mais claramente a tratar a cultura como objeto de estudo independente, buscando avaliar as variáveis que afetavam a sua evolução mesmo que sem referência direta ao comportamento individual. A análise da cultura como objeto específico de pesquisa ganha mais fôlego com a proposição por Sigrid Glenn do conceito de metacontingência e com os trabalhos posteriores da autora. $\mathrm{O}$ conceito de metacontingência foi alterado em sucessivas publicações de Glenn, aumentando o foco na recorrência de contingências comportamentais entrelaçadas e dos seus produtos agregados. Além disso, a consequência comum ao grupo deixou de ser caracterizada como um evento necessariamente a longo prazo, sugerindo que ela também poderia ser um evento imediato. O artigo Comportamento individual, cultura e mudança social (Glenn, 2004) - cuja tradução este texto introduz - pode ser entendido como uma síntese de muitas das discussões anteriores sobre o tema e como marco do estabelecimento de muitos conceitos que continuam a ser empregados pelos interessados no tema. $\mathrm{O}$ conceito de metacontingência continuou passando por reformulações após o artigo de Glenn publicado em 2004, mas apenas no início do presente século experimentos que explicitamente o empregam começaram a ser realizados.

Palavras-chave: metacontingência, macrocontingência, evolução cultural, comportamento social.

\section{ABSTRACT}

Despite its focus in the study of the behavior of individual organisms, Behavior Analysis has dealt for decades with social and cultural phenomena. Only in the 1980s, however, it began more clearly to treat culture as an object of independent study, seeking to assess the variables affecting its evolution even without direct reference to individual behavior. The analysis of culture as a specific subject matter gains more impetus with the proposition by Sigrid Glenn of the concept of metacontingency and with her subsequent works. The concept of metacontingency was changed in successive publications by Glenn, increasing the focus on the recurrence of interlocking behavioral contingencies and its aggregate products. Furthermore, the common consequence to the group was no longer characterized as a necessarily long-term event, suggesting that it could also be an immediate event. The paper entitled Individual Behavior, Culture and Social Change (Glenn, 2004) - whose translation to Portuguese this text introduces - can be understood as a synthesis of many previous discussions on the subject and as a mark of the establishment of many concepts that continue to be employed by those interested in the topic. The concept of metacontingency still underwent some reformulations after Glenn's article published in 2004, but only at the beginning of this century experiments that explicitly employ it began to be conducted.

Key words: metacontingency, macrocontingency, cultural evolution, social behavior.

\footnotetext{
*Bolsista do CNPq - Brasil. Os autores agradecem a Henrique V. B. R. Angelo e Natália S. Marques pelos comentários e sugestões a respeito de versões prévias desse texto. Correspondências a respeito do presente trabalho podem ser enviadas para Angelo A. S. Sampaio: Av. Prof. Mello Moraes, 1721 - Bloco A, São Paulo - SP, CEP: 05508-030; angelo.sampaio@ univasf.edu.br
} 


\section{O PAPEL DE SIGRID GLENN E DO CONCEITO DE METACONTINGÊNCIA NO ESTUDO DA CULTURA PELA ANÁLISE DO COMPORTAMENTO}

Apesar de seu foco no estudo do comportamento de organismos individuais, a Análise do Comportamento tem tratado há décadas de fenômenos sociais e culturais. Em Walden Two, Skinner (1948) sugeriu como princípios comportamentais poderiam ser empregados no planejamento cultural e discutiu ética, política e evolução cultural. Os primeiros manuais da área (Keller \& Schoenfeld, 1950; Skinner, 1953) também trataram longamente de comportamento social e cultura. Além disso, análises experimentais da cooperação, da competição, de contingências grupais e outros fenômenos sociais foram realizadas ao menos desde a década de 1950 (ver, e.g., a coletânea de trabalhos em Ulrich \& Mountjoy, 1972). A grande maioria desses trabalhos, contudo, voltava-se para os efeitos de variáveis sociais ou da cultura sobre o comportamento individual; a principal unidade de análise ainda era a contingência tríplice, mesmo quando mais de uma contingência tríplice precisa ser analisada simultaneamente (Andery, 2011).

Apenas na década de 1980, começou-se mais claramente a tratar a cultura como objeto de estudo independente, buscando avaliar as variáveis que afetavam a sua evolução mesmo que sem referência direta ao comportamento individual. A cultura deixou de ser vista apenas como uma variável independente e passou também a ser analisada como variável dependente (Andery, 2011). Um passo fundamental nessa direção foi a publicação do artigo Selection by Consequences, no qual Skinner (1981) enfatizou que culturas evoluem por um processo descrito como um terceiro nível de seleção pelas consequências (o primeiro sendo a seleção natural e o segundo o condicionamento operante). Isso deslocou o interesse de como contingências socialmente organizadas afetam o comportamento individual, para como determinadas contingências socialmente organizadas surgem, mantêm-se e extinguem-se.

A análise da cultura como objeto específico de pesquisa ganha mais fôlego com a proposição por Sigrid Glenn do conceito de metacontingência (Glenn, 1986) e com os trabalhos posteriores da autora. Tourinho (2009) sugere que uma nova agenda de pesquisas teria se estabelecido: a análise comportamental da cultura. Muita discussão e muitas reformulações conceituais ocorreram nas décadas de 1980 e 1990 (ver Martone \& Todorov, 2007; Andery, Vieira, Bullerjhann \& Amorim, 2008). O artigo intitulado Individual behavior, culture, and social change (Glenn, 2004) pode ser entendido como um momento de síntese de muitas das discussões anteriores sobre o tema e como marco do estabelecimento de muitos conceitos que continuam a ser empregados pelos interessados no tema. Sua tradução, 10 anos após sua publicação, faz jus às suas repercussões internacionais e, em especial, no Brasil - inclusive no estabelecimento de linhas de pesquisa voltadas para a análise experimental de metacontingências e macrocontingências (e.g., Borba et al., 2014; Costa, Nogueira \& Vasconcelos, 2012;
Saconatto \& Andery, 2013). Essa tradução se soma a e complementa outros artigos de Glenn já traduzidos para o português (Glenn, 1986/2005; Glenn \& Malott, 2004/2005).

Para contextualizar o artigo de Glenn (2004), apresentamos a seguir um breve histórico do conceito de metacontingência, destacamos a relevância do artigo, modificações posteriores sofridas pelo conceito de metacontingência e alguns desenvolvimentos recentes na análise comportamental da cultura.

\section{O CONCEITO DE METACONTINGÊNCIA NA OBRA DE SIGRID GLENN DE 1986 A 2004}

Ao analisar o romance utópico Walden Two (Skinner, 1948), Glenn (1986) buscou esclarecer "a distinção traçada por Skinner entre a seleção do comportamento operante em indivíduos e a seleção de práticas culturais em sociedades" (p. 2). O conceito de metacontingência foi então apresentado e definido pela primeira vez como

a unidade de análise que descreve as relações funcionais entre uma classe de operantes, com cada operante tendo sua própria consequência imediata e única, e uma consequência em longo prazo comum a todos os operantes da metacontingência. Metacontingências precisam ser mediadas por contingências de reforço arranjadas socialmente. (Glenn, 1986, p. 2)

Nesse momento, o conceito de metacontingência aparece apenas como um conjunto de operantes que produz algo em comum. As relações entre os operantes envolvidos e destes com a consequência comum ainda precisavam ser claramente especificadas.

Em 1988, ao buscar uma integração da Análise do Comportamento com o Materialismo Cultural do antropólogo Marvin Harris, Glenn definiu metacontingência como

a unidade de análise que engloba uma prática cultural, em todas as suas variações, e o efeito agregado [aggregate outcome] de todas as variações presentes. $\mathrm{O}$ produto das práticas culturais deve, é claro, ser especificado empiricamente. . . . A relação funcional entre as práticas culturais e seus produtos retroage às culturas por meio do processo de seleção. (p. 168)

Nesse momento, Glenn (1988) já passa a definir prática cultural como sinônimo de um conjunto de contingências entrelaçadas e a destacar a ação seletiva do ambiente externo (Martone \& Todorov, 2007).

Em 1989, Glenn continuou buscando uma síntese entre Análise do Comportamento e Materialismo Cultural ao tratar das concepções divergentes sobre "linguagem" presentes nessas perspectivas. Nesse estudo, a autora propôs qual seria o papel do comportamento verbal na evolução cultural, sem modificar seus principais conceitos (e.g., práticas culturais e metacontingência) para tratar do tema.

Posteriormente, Glenn (1991) buscou apresentar um amplo quadro de referência dentro do qual os processos comportamentais e culturais se inserem: "Este capítulo é sobre processos comportamentais e processos 
culturais, como eles se relacionam e como ambos se relacionam com a evolução biológica" (p. 39). Nesse momento, o conceito de prática cultural ganha destaque e é apresentado de modo um pouco distinto dos trabalhos anteriores da autora: "Práticas culturais envolvem a repetição de comportamento operante análogo entre indivíduos de uma mesma geração e entre gerações de indivíduos (Glenn, 1988; Malagodi \& Jackson, 1989)" (p. 60). Para a autora,

os elementos necessários de uma prática cultural são: (1) conteúdo comportamental adquirido durante o tempo de vida de cada participante; (2) ambientes comportamentais de um ou mais dos participantes que incluam (mas não se limitem a) o comportamento de membros da mesma espécie; (3) a aquisição repetida do comportamento dentro de uma mesma e entre gerações (p. 60).

Ainda de acordo com Glenn (1991), práticas culturais poderiam envolver contingências comportamentais entrelaçadas e sua análise seria mais complexa quando elas envolvessem um produto agregado: um efeito dos comportamentos envolvidos que não poderia ser produzido por um indivíduo agindo sozinho.

Nessa ocasião, Glenn emprega conceitos do Materialismo Cultural (nomoclone, permaclone, sistema permaclônico) para definir uma metacontingência e a diferencia dos termos "contingências culturais" (usado por ela mesma e por outros) e "megacontingências" (Vargas, 1985). As características principais do conceito permanecem inalteradas em relação à sua publicação anterior: "Metacontingências são relações contingentes entre práticas culturais e produtos destas práticas . . . . são relações funcionais no nível cultural de análise cuja existência deriva de, mas não é equivalente a, contingências comportamentais." (Glenn, 1991, p. 62).

Em 2003, Glenn enfatiza o diálogo com a Biologia Evolutiva, aplicando aos fenômenos culturais a abordagem geral proposta por Hull, Langman e Glenn (2001) para lidar com a seleção. Esses últimos autores sugeriram que o processo de seleção funcionaria de modo análogo na evolução biológica, na reação do sistema imunológico aos antígenos e na aprendizagem operante. A seleção envolveria dois subprocessos relacionados replicação e interação - executados por diferentes entidades - replicadores e interatores, respectivamente. A entidade que evolui, por fim, seria sempre uma linhagem. $\mathrm{Na}$ seleção natural, os replicadores (e.g., genes) dariam conta da retenção de características organísmicas em uma espécie, enquanto os interatores (e.g., organismos ou colônias) seriam os todos coesos que interagem diferencialmente com o ambiente. Esta interação resultaria em replicação diferencial dos genes em linhagens orgânicas. No caso da seleção operante, os interatores seriam respostas (ou atos) que se adaptariam diferencialmente ao ambiente selecionador (consequências comportamentais), enquanto os replicadores seriam os componentes neurais dessas respostas e a linhagem resultante, por fim, seria um operante.

Glenn (2003) introduz os conceitos de linhagem culturo-comportamental e de linhagem cultural (que serão retomados em 2004). Uma linhagem culturocomportamental envolveria a replicação, por meio de aprendizagem social, de contingências operantes entre diferentes indivíduos e faria a ponte entre seleção operante e seleção cultural. Uma linhagem cultural, por sua vez, envolveria a recorrência de contingências comportamentais entrelaçadas com base nas consequências produzidas por elas. Um maior esclarecimento desses conceitos, contudo, precisou aguardar a publicação do artigo de 2004.

Em suma, o conceito de metacontingência foi alterado em sucessivas publicações de Glenn (1986, 1988, 1989, 1991, 2003, 2004), aumentando o foco na recorrência de contingências comportamentais entrelaçadas e dos produtos agregados resultantes desse entrelaçamento. Além disso, a consequência comum ao grupo deixou de ser caracterizada como um evento necessariamente a longo prazo, sugerindo que ela também poderia ser um evento imediato.

\section{A RELEVÂNCIA DO ARTIGO COMPORTAMENTO INDIVIDUAL, CULTURA E TRANSFORMAÇÃO SOCIAL}

Em 2004, Glenn publicou o artigo Individual behavior, culture, and social change, no qual continuou tratando de fenômenos culturais a partir de princípios e conceitos familiares a analistas do comportamento. Começando com a apresentação da noção de seleção operante, a autora discute como fenômenos comportamentais podem aumentar em termos de complexidade de modo que eventualmente passem a caracterizar relações comportamentais entre mais de um organismo. O caminho até a emergência de fenômenos culturais é traçado ao abordar a semelhança de conteúdos ambientais em contingências operantes, as relações entre herança biológica e cultura e pela descrição da noção de linhagens culturo-comportamentais.

Um aspecto central do artigo de Glenn (2004) é a introdução dos conceitos de macrocomportamento e macrocontingência. O termo macrocomportamento é sugerido para se referir à classe de comportamentos que integram uma prática cultural. Uma prática cultural passa a ser definida (diferentemente de publicações anteriores) como "padrões similares de conteúdo comportamental, normalmente como resultado de similaridades nos ambientes" (p. 140). Glenn ainda destaca que

qualquer prática cultural pode ser composta por comportamentos gerados independentemente e também por comportamentos transmitidos socialmente. . . . similaridade no conteúdo comportamental de muitos indivíduos é suficiente para se considerar o comportamento agregado uma prática cultural, mas não é suficiente para se assumir que haja transmissão cultural, e ainda menos suficiente para se assumir uma origem comum. (p. 140)

$\mathrm{O}$ conceito de macrocontingência foi descrito por Glenn (2004) como "a relação entre uma prática cultural e a soma agregada de consequências do macrocomportamento que constitui a prática" (p. 142). Com esse conceito, distinguem-se dois tipos de situações 
que envolvem resultados somados ou agregados dos comportamentos de mais de um indivíduo. Uma metacontingência seria uma unidade de análise de linhagens culturais, tratando da recorrência contínua de padrões de interação entre dois ou mais indivíduos (contingências comportamentais entrelaçadas) que produzem resultados diferentes da soma do comportamento individual (produto agregado). $\mathrm{O}$ conceito de macrocontingência, por sua vez, trataria do efeito cumulativo do comportamento de muitas pessoas que não funciona como consequência comportamental, nem implica em entrelaçamento das contingências envolvidas, nem em linhagens culturais. A própria autora destaca que Todorov, Moreira e Moreira (2004) já tinham chamado atenção para a diferença entre metacontingências e macrocontingências (sem utilizar este termo) e fornecido exemplos destas últimas.

O conceito de metacontingência é utilizado no artigo para novamente discutir questões envolvendo a complexidade crescente de fenômenos culturais. Ao longo do texto, o artigo aborda relações entre os conceitos de contingências operantes, metacontingências e macrocontingências e discute como os conceitos apresentados podem ser utilizados para elaborar planos de mudanças culturais. Vale a pena destacar que este foco na mudança cultural é uma das características que distingue o trabalho de Glenn e outros analistas do comportamento interessados no tema da cultura (e.g., Biglan, 2003; Mawhinney, 1999) de outras perspectivas que tratam de evolução cultural, como as de Richerson e Boyd (2005).

\section{ALTERAÇÕES NO CONCEITO DE METACONTINGÊNCIA APÓS 2004}

$\mathrm{O}$ conceito de metacontingência continuou passando por reformulações após o artigo de Glenn publicado em 2004. Ao discutir a aplicação do conceito a organizações, Glenn e Malott (2004) introduziram um terceiro elemento, além das contingências comportamentais entrelaçadas e do produto agregado: o sistema receptor (receiving system): "Em organizações, metacontingências apresentam três componentes: contingências comportamentais entrelaçadas, seu produto agregado e seu sistema receptor. O sistema receptor é o recipiente do produto agregado e, assim, funciona como ambiente selecionador das contingências comportamentais entrelaçadas (cf. Brethower, 2000)." (p. 100). De acordo com as autoras, ao menos em organizações, produtos agregados não exercem um efeito seletivo direto sobre contingências comportamentais entrelaçadas, exercendo tal efeito apenas através de um sistema social que absorve ou consome tais produtos. Posteriormente, o evento ambiental com função selecionadora proveniente de um sistema receptor passou a ser denominado de consequência cultural (Vichi, Andery \& Glenn, 2009), resgatando um termo que a autora já utilizara em artigos anteriores (Glenn, 1986, 1988, 2003).

Desse modo, atualmente o conceito de metacontingência descreve relações funcionais entre (a) ações coordenadas de um grupo de indivíduos contingências comportamentais entrelaçadas (CCEs) que geram (b) um produto agregado decorrente desta coordenação e (c) uma mudança ambiental contingente à relação entre CCE e produto agregado - consequência cultural (para outras discussões conceituais sobre a noção de metacontingência, ver Houmanfar \& Rodrigues, 2006; Houmanfar, Rodrigues \& Ward, 2010).

\section{DESENVOLVIMENTOS RECENTES: O SURGIMENTO DA EXPERIMENTAÇÃO SOBRE METACONTINGÊNCIA E MACROCONTINGÊNCIA}

Após quase 20 anos de discussões teóricas baseadas em poucos dados empíricos coletados sistematicamente, apenas no início do presente século experimentos que explicitamente empregam o conceito de metacontingência começaram a ser realizados (Vichi, 2004 - posteriormente publicado por Vichi, Andery \& Glenn, 2009). Com base nesse conceito, linhas de pesquisa em diversas universidades brasileiras e no exterior têm produzido continuamente resultados experimentais sobre fenômenos culturais (e.g., Borba et al., 2014; Costa, Nogueira \& Vasconcelos, 2012; Ortu, Becker, Woelz \& Glenn, 2012; Saconatto \& Andery, 2013). Além de pesquisas básicas, recentemente, Camden e Ludwig (2013) relataram o primeiro estudo aplicado elaborado com o emprego do conceito - tratando do absenteísmo em uma organização hospitalar. $\mathrm{O}$ fomento dessas pesquisas experimentais é provavelmente a maior contribuição do conceito de metacontingência à Análise do Comportamento. Muitas questões metodológicas permanecem em aberto, mas o acúmulo de evidências parece ter facilitado a própria discussão conceitual e gerado questões antes não imaginadas.

Enquanto a experimentação sobre metacontingência ocorreu após quase duas décadas, o primeiro experimento sobre macrocontingências (Borba et al., 2014) foi publicado 10 anos após a introdução do conceito. Se, por um lado, o intervalo diminuiu, por outro, ele ainda parece deveras grande. O futuro da área pode depender de uma aproximação cada vez maior e mais rápida entre análises experimentais e discussões conceituais. Os analistas do comportamento brasileiros tiveram um papel pioneiro na experimentação da área e devem buscar ter a mesma iniciativa em termos desse novo desafio.

\section{REFERÊNCIAS}

Andery, M. A. P. A. (2011). Comportamento e cultura na perspectiva da análise do comportamento. Perspectivas em Análise do Comportamento, 2, 203-217.

Andery, M. A. P. A., Vieira, M. C., Bullerjhann, P. B., \& Amorim, V. C. (2008) A evolução do conceito de metacontingência: uma análise por meio a definição e dos exemplos empregados por Sigrid S. Glenn. Painel apresentado no XVII Encontro Brasileiro de Psicoterapia e Medicina Comportamental. Campinas, São Paulo.

Biglan, A. (2003). Selection by consequences: One unifying principle for a transdisciplinary science of prevention. Prevention Science, 4 (4), 213-232. 
Borba, A., Silva, B. R., Cabral, P. A. A., Souza, L. B., Leite, F. L., \& Tourinho, E. Z. (2014). Effects of exposure to macrocontingencies in isolation and social situations in the production of ethical self-control. Behavior and Social Issues, 23, 5-19.

Camden, M. C., \& Ludwig, T. D. (2013). Absenteeism in health care: Using interlocking behavioral contingency feedback to increase attendance with certified nursing assistants. Journal of Organizational Behavior Management, 33, 165-184.

Costa, D., Nogueira, C. P. V., \& Vasconcelos, L. A. (2012). Effects of communication and cultural consequences on choices combinations in INPDG with four participants. Revista Latinoamericana de Psicología, 44 (1), 121-131.

Glenn, S. S. (1986). Metacontingencies in Walden Two. Behavior Analysis and Social Action, 5, 2-8.

Glenn, S. S. (1988). Contingencies and metacontingencies: Toward a synthesis of behavior analysis and cultural materialism. The Behavior Analyst, 11, 161-179.

Glenn, S. S. (1989). Verbal behavior and cultural practices. Behavior Analysis and Social Action, 7 (1-2), 10-15.

Glenn, S. S. (1991). Contingencies and metacontingencies: Relations among behavioral, cultural, and biological evolution. Em P. A. Lamal (Ed.), Behavioral analysis of societies and cultural practices (pp. 39-73). New York: Hemisphere.

Glenn, S. S. (2003). Operant contingencies and the origin of cultures. Em K. A. Lattal, \& P. N. Chase (Eds.), Behavior theory and philosophy (pp. 223-242). New York: Kluver/Plenum.

Glenn, S. S. (2004). Individual behavior, culture, and social change. The Behavior Analyst, 27, 133-151.

Glenn, S. S. (2005). Metacontingências em Walden Dois. Em J. C. Todorov, R. C. Martone, \& Moreira, M. B. (Orgs.), Metacontingências: Comportamento, cultura e sociedade (pp. 13-28). Santo André: Esetec. (Originalmente publicado em 1986).

Glenn, S. S., \& Malott, M. E. (2004). Complexity and selection: implications for organizational change. Behavior and Social Issues, 13, 89-106.

Glenn, S. S., \& Malott, M. E. (2005). Complexidade e seleção: Implicações para a mudança organizacional. Em J. C. Todorov, R. C. Martone, \& Moreira, M. B. (Orgs.), Metacontingências: Comportamento, cultura e sociedade (pp. 101-119). Santo André: Esetec. (Originalmente publicado em 2004).

Houmanfar, R., \& Rodrigues, N. J. (2006). The metacontingency and the behavioral contingency: Points of contact and departure. Behavior and Social Issues, 15, 15-30.

Houmanfar, R., Rodrigues, N. J. \& Ward, T. A. (2010). Emergence and metacontingency: Points of contact and departure. Behavior and Social Issues, 19, 78-103.

Hull, D. L., Langman, R. E., \& Glenn, S. S. (2001). A general account of selection: Biology, immunology, and behavior. Behavioral and Brain Sciences, 24, 511573.
Keller, F. S., \& Schoenfeld, W. N. (1950). Principles of Psychology: A systematic text in the science of behavior. New York: Appleton-Century-Crofts.

Martone, R. C., \& Todorov, J. C. (2007). O desenvolvimento do conceito de metacontingência. Revista Brasileira de Análise do Comportamento, 3, 181-190.

Mawhinney, T. C. (1999). Cumulatively large benefits of incrementally small intervention effects: Costing metacontingencies of chronic absenteeism. Journal of Organizational Behavior Management, 18 (4), 83-95.

Ortu, D., Becker, A. M., Woelz, T. A. R., \& Glenn, S. S. (2012). An iterated four-player prisoner's dilemma game with an external selecting agent: A metacontingency experiment. Revista Latinoamericana de Psicología, 44 (1), 111-120.

Richerson, P. J., \& Boyd, R. (2005). Not by genes alone. Chicago: University of Chicago Press.

Saconatto, A. T., \& Andery, M. A. P. A. (2013). Seleção por metacontingências: Um análogo experimental de reforçamento negativo. Interação em Psicologia, 17, 110.

Skinner, B. F. (1948). Walden Two. New York: Macmillan.

Skinner, B. F. (1953). Science and human behavior. New York: Free Press.

Skinner, B. F. (1981). Selection by consequences. Science, 213, 501-504.

Todorov, J. C., Moreira, M. B., \& Moreira, M. (2004). Metacontingencies: Interlocked and unrelated contingencies. Em T. C. C. Grassi (Org.), Contemporary challenges in the behavioral approach: A Brazilian overview (pp. 221-225). Santo André, SP: ESETec Editores Associados.

Tourinho, E. Z. (2009). A análise comportamental da cultura: Introdução a uma agenda de pesquisa. Em M. R. de Souza \& F. C. S. Lemos. (Orgs.), Psicologia e compromisso social: Unidade na diversidade (pp. 235251). São Paulo: Escuta.

Ulrich, R. E., \& Mountjoy, P. T. (1972). The experimental analysis of social behavior. New York: AppletonCentury-Crofts.

Vargas, E. A. (1985). Cultural contingencies: A review of Marvin Harris's Cannibals and Kings. Journal of the Experimental Analysis of Behavior, 43, 419-428.

Vichi, C., Andery, M. A. P. A., \& Glenn, S. S. (2009). A metacontingency experiment: The effects of contingent consequences on patterns of interlocking contingencies of reinforcement. Behavior and Social Issues, 18, 4157. 